\title{
COMMENTS ON FUJIWARA'S AND SUZUKI'S PAPERS
}

\author{
NORIO YAMADA \\ University of Tsukuba
}

YASUAKI FUJIWARA, 'On the function of alliteration', concentrates his attention on the function of alliteration in Germanic verse. Specifically, he argues that in Germanic languages alliteration plays an active role in determining the structural properties of their verse, and that these properties may be regarded as metrical objects reflecting certain aspects of their linguistic (in particular phonological) structures.

First, Fujiwara makes a critical survey of a fairly extensive literature on Old Germanic metrics, including in particular Sievers 1893, Halle \& Keyser 1971, and Russom 1987, claiming that none of them have so far elucidated satisfactorily two important structural characteristics of Germanic alliterative verse: (i) its division of a line into two half-lines and (ii) its use of alliteration.

His alternative account is based crucially upon the hypothesis that among syllables bearing primary stress alliterating syllables are more prominent than non-alliterating ones. It follows from this hypothesis that a trochaic rhythm will be realized over a half-line in the case of single alliteration, and also over a long line in the case of double alliteration. $\mathrm{He}$ concludes that alliteration functions as an indispensable metrical apparatus for dividing a sequence of words into half- or long lines, and determining their characteristic trochaic rhythm. What seems most interesting in his discussion of Germanic metrics is his observation that the essentially trochaic stress pattern of Old Germanic words is directly reflected in the metrical structure of its verse.

Next, Fujiwara turns to a consideration of some important metrical properties of Sir Gawain and the Green Knight, a representative example of Middle English alliterative verse. First, he points out that lifts are no longer restricted to long stressed syllables as in Old English poetry, but may correspond to any variety of stressed syllables. In this connection, recall Suzuki's assumption that in OE lifts had to be associated with the level of FоOT as characterized by Keyser \& O'Neil 1985. However, Fuji- 
wara asserts that this restriction does not hold at least for ME poetry. A question to be raised, then, is why the above constraint on OE poetry came to be abandoned in ME. Though this is certainly a very interesting question, we are at present obliged to relegate it to future investigation.

Furthermore, Fujiwara observes that most of the first half-lines contained in the above poetical work exhibit either double or triple alliteration. Basing himself on this observation, he claims that most of its long lines have precisely the same trochaic rhythm as that of OE half-/ long lines. And he comes to the conclusion that in ME poetry the device of alliteration is employed obligatorily so as to divide a sequence of words into long lines, and to determine their trochaic rhythm. However, in cases where both left and right half-lines exhibit either single or double alliteration, the resultant long lines clearly cannot be characterized as those having a trochaic rhythm. Can we dismiss such lines simply as marked cases? Or should we believe that there must be some principled ground for their existence? To answer this question, however, we must apparently await further research.

Finally, Fujiwara claims that it was a trochaic rhythm that was the most prevalent stress pattern for Late Middle English words, and that for that very reason it was possible for long lines to have the same rhythmic pattern. However, though he may be right in claiming that for Late ME words the trochaic stress pattern had the preponderance over the iambic rhythm, yet it must be noted that his factual observations are made strictly on the level of surface phonetic representations. If it turns out that a generalization that seems to underlie the observed phonetic facts should be formulated as something like the Romance Stress Rule (cf. Halle \& Keyser 1971: 101), then despite his claim it will no longer be possible to maintain that the alleged trochaic rhythm of long lines may reflect aspects of the phonological regularities of Late ME.

SEIICHI SuZUKI, 'Old Germanic metrics in the light of Indo-European metrics and accent typology', attempts to explain various structural properties of Germanic alliterative verse in diachronic terms from the standpoint of Indo-European metrics.

He points out some metrical innovations that seem to have occurred in Old Germanic. The first innovation he points out is that a single metrical line came to be characterized in terms of the hierarchical organization of the longer and the shorter schemes. (He assumes that the longer schemes may be inherited from Indo-European, while the shorter one shared by both Germanic and Old Irish.) He says that the same 
innovation provided the basis for the five attested metrical types of Germanic, i.e. Types A-E. Furthermore, he asserts that in Germanic the shorter scheme became associated with the level of Foot as characterized by Keyser \& O'Neil 1985, a fact which he claims is responsible for the phenomenon of resolution. Thirdly, he puts forward the hypothesis that the initial part of a line was regularized on the basis of the metrical patterns that might be admissible in the cadence. Finally, he claims that as a result of this process of regularization the original two longer schemes [5 $\mid 3]$ and [4|4] merged into the latter structure, which caused new metrical types with initial weak positions, i.e. Types $B$ and $C$, to be introduced into the cadence.

Next, Suzuki tries to give rationale to the obligatory status of alliteration in Germanic verse. He convincingly argues that it is precisely because in Germanic the shorter scheme became associated with the level of stress, or more exactly, Foot that the device of alliteration necessarily came to be utilized there as an obligatory means of giving metrical salience to certain strong positions in the line. He notes, however, that the situation was quite different in Old Irish, where the shorter scheme was simply associated with the mere level of syllable, so that alliteration was at best ornamental in function.

Last but not least, Suzuki insists that metrical properties of a language may depend on its phonological system. According to him, the Germanic innovation of the shorter scheme getting associated with the level of Foot was due precisely to the fact that the hierarchical structure in question was independently available to some phonological processes of the relevant languages. He goes on to compare Old Germanic with Old Irish, completely devoid of such a metrical innovation, and claims that the latter language had no phonological processes referring crucially to Foot structures.

However, some difficulties seem to lie in his accounts of half-lines consisting of five metrical positions. First, he says that it was because of the metrically free status of the $a$-verse as against the restricted nature of the $b$-verse that Types aA and $\mathrm{aD}$, beginning with drop, were almost invariably confined to the $a$-verse. But such an account does not always seem to hold good, for Types B and C, similarly beginning with drop, were indeed introduced into the cadence. Second, those half-lines which might be analyzed as belonging to *Type $\mathrm{aE}(\mathrm{x} / \mathrm{x} \mathrm{x} /)$ have never been known to exist. Though in his paper he does not explain why this is the case, whether the absence of such half-lines is fortuitous or prin- 
cipled seems to be an important question requiring further examination. Third, he claims that the configuration given in 15 of his paper, which allegedly resulted from the regularization of the initial on the model of the cadence, cannot be interpreted as equivalent to any of the five basic metrical types, and that as a result the structure in question came to be established as an independent metrical type, viz. Type $D^{*}$. Certainly 15 must not be interpreted as equivalent to, say, Types A or D. Unfortunately, however, he tells us no reason why it cannot be so interpreted. Lastly, the appearance of those half-lines which consist of five metrical positions (i.e. Types $\mathrm{aA}, \mathrm{aD}$, and $\mathrm{D}^{*}$ ) seems to override the alleged tendency for [5 $\mid 3]$ to be replaced by [4|4]. Therefore, there still seems to remain much room for controversy as to the raison d'être of the Types in question. 